- 研究报告・

\title{
珍稀植物连香树在其中国分布区北缘的 种子性状及幼苗更新限制
}

李 晶 $1,2,3,4$ 周天阳 ${ }^{1,2,3}$ 鲁雪丽 $^{5}$ 李新涛 $^{5}$ 孙 斌 孟红杰 $^{1,2 *}$

1 (中国科学院水生植物与流域生态重点实验室, 中国科学院武汉植物园, 武汉 430074)

2 (中国科学院核心植物园保护生物学中心, 武汉 430074)

3 (中国科学院大学, 北京 100049)

4 (长江大学, 湖北荆州 434025)

5 (河南奕川县龙峪湾林场, 河南栾川 471500)

6 (甘肃小陇山林业实验局东岔林场, 甘肃天水 741036)

摘要: 连香树(Cercidiphyllum japonicum)是第三纪子遗植物, 存在严重的幼苗更新限制。为验证生活史早期(种子萌 发)限制中国分布区北缘连香树种群幼苗更新, 并探讨其主要成因, 本研究在秦岭和太行山脉采集不同种源地的 种子, 测定其形态性状、营养元素含量和质量、不同拒存时间的活力及不同温度条件下的萌发性状, 通过方差分 析、相关分析等方法对不同种源地的种子性状进行分析。结果表明: 在中国分布区北缘, 其种子长度 $(P<0.001)$ 、 萌发率 $(P<0.001)$ 、平均萌发时间 $(P<0.001)$ 、氮 $(P<0.05)$ 和磷含量 $(P<0.001)$ 在不同种源间存在显著差异; 而在 区域尺度上(秦岭与太行山), 仅种子碳含量存在显著差异 $(P<0.01)$ 。天水种群的种子萌发率最高 $(21.77 \%)$, 平均萌 发时间最长(11.12 d); 橸川的萌发率最低(1.38\%), 平均萌发时间最短 $(3.47 \mathrm{~d})$ 。在 $25^{\circ} \mathrm{C}$ 条件下, 济源种群的种子萌 发率显著高于 $10^{\circ} \mathrm{C} 、 15^{\circ} \mathrm{C}$ 和 $20^{\circ} \mathrm{C}$ 条件下 $(P<0.05)$, 而其他种源地的萌发率在不同温度条件下无显著差异。在 4 个 温度条件下, 森川种群种子的初始萌发时间无显著差异, 而其他 4 个种源地的初始萌发时间都随温度升高而缩短。 相关分析结果表明, 种子萌发率与种子活力密切相关, 而种子活力与种子质量、种子的氮和磷含量显著相关。在 中国分布区北缘, 连香树种子的自身属性(质量、氮和磷含量)通过影响种子活力间接影响萌发率; 且种子萌发对温 度的响应主要表现在萌发时间上。本研究证实种子萌发是限制连香树种群幼苗更新的关键阶段, 主要原因如下: (1)连香树种子在9月成熟后, 10月的温度仍适宜种子萌发, 但较短生长期的幼苗在冬季低温下不能存活; (2)连香树 种子萌发率低(14.4\%); (3)第二年春天种子活力骤降。

关键词: 连香树; 更新限制; 种子质量; 种子活力; 萌发率; 分布区北缘; 秦岭-太行山脉

\section{Seed traits and recruitment limitation of northern marginal Cercidiphy- Ilum japonicum populations in China}

\author{
Jing Li ${ }^{1,2,3,4}$, Tianyang Zhou ${ }^{1,2,3}$, Xueli $\mathrm{Lu}^{5}$, Xintao $\mathrm{Li}^{5}$, Bin Sun ${ }^{6}$, Hongjie Meng ${ }^{1,2^{*}}$ \\ 1 Key Laboratory of Aquatic Botany and Watershed Ecology, Wuhan Botanical Garden, Chinese Academy of Sciences, \\ Wuhan 430074 \\ 2 Center of Conservation Biology, Core Botanical Gardens, Chinese Academy of Sciences, Wuhan 430074 \\ 3 University of Chinese Academy of Sciences, Beijing 100049 \\ 4 Yangtze University, Jingzhou, Hubei 434025 \\ 5 Long Yu Wan Forest Farm of Luanchuan County, Luanchuan, Henan 471500 \\ 6 Dongcha Forest Farm of Xiaolongshan Forestry Experimental Bureau of Gansu, Tianshui, Gansu 741036
}

Abstract: Cercidiphyllum japonicum is a Tertiary relict tree, and recruitment limitation leads to the population declining dramatically. However, the causes of recruitment limitation are currently unclear. This study tests whether early life history traits (seed germination) may limit seedling recruitment of northern $C$.

收稿日期: 2020-03-12; 接受日期: 2020-06-03

基金项目: 国家自然科学基金(31800347)和中国博士后科学基金(2019M652742)

* 通讯作者 Author for correspondence. E-mail: menghongjie@wbgcas.cn 
japonicum populations in China. In this study, we collected C. japonicum seeds in the Qinling-Taihang Mountains and measured their seed morphological traits, seed nutrient content, seed mass, seed vitality, and seed germination. ANOVA and correlation analysis results showed that: (1) There were significant differences in seed length, germination percentage, mean germination time (MGT), and seed nitrogen and phosphorus contents among C. japonicum populations. (2) In the Tianshui population, the percentage of germinating seeds was the highest (21.77\%), and MGT was the longest (11.12 d), while the opposite results were found in Luanchuan population (germination percentage $=1.38 \%$, and MGT $=3.47 \mathrm{~d}$ ). (3) The percentage of germination of the Jiyuan population was higher at $25^{\circ} \mathrm{C}$ than at other temperatures $\left(10^{\circ} \mathrm{C}\right.$, $15^{\circ} \mathrm{C}$ and $20^{\circ} \mathrm{C}$ ), whereas the germination percentages of Tianshui, Ningshan, Luanchuan and Qinshui populations had no significant differences at these different temperatures. Additionally, there were no significant differences in days of the first germination record $\left(T_{0}\right)$ in Luanchuan population at four temperature levels, while $\mathrm{T}_{0}$ decreased with increasing germination temperature in the other provenances. (4) Germination percentage was significantly correlated with seed vitality, which was positively related with seed mass, and seed nitrogen and phosphorus contents. Seed intrinsic attributes (seed mass, seed nitrogen and phosphorus contents) influenced seed vitality which directly influenced germination percentage. Different provences had difference germination responses to temperature, notably in $\mathrm{T}_{0}$ and MGT. In this study, we found evidence of seed germination limiting seedling recruitment of northern Chinese C. japonicum populations. The main causes were as follow: (1) Seed may germinate in October after maturation in September, but the seedlings have short growing period and could not survive under low temperature during winter. (2) Seeds have low germination percentage. (3) Seed vitality decrease abruptly in coming spring.

Key words: Cercidiphyllum japonicum; recruitment limitation; seed mass; seed vitality; germination percentage; northern marginal distribution; Qinling-Taihang Mountains

植物的自然更新过程包括结实、种子萌发、幼 苗建成等阶段, 对物种分布、种群维持以及群落演 替有重要的影响(Fraaije et al, 2015; Huang et al, 2016)。种子是植物生活史周期中的关键阶段, 极易 受到生物和非生物因素的影响, 是自然更新障碍最 易发生的阶段(Kubo et al, 2004; 李宁等, 2011)。种 子的性状与种子萌发、幼苗建成等自然更新过程密 切相关, 反映了植物对环境改变的响应(Moles et al, 2007)。通过研究种子性状(形态、萌发、元素性状 等)及其影响因子, 可以探究植物的更新过程, 预测 种群动态。但目前通过整合种子的形态、元素(碳、 氮和磷) 和萌发性状来揭示幼苗更新障碍的相关报 道较少。

种子性状受地理、气候因子和遗传差异等因素 的影响(Murray et al, 2004; Guo et al, 2010; Sudrajat, 2016)。种子的萌发过程不仅受环境因子(水分、温 度和光照等)和遗传差异的影响, 也受其自身属性 (种子质量、元素含量)的影响(Masaki et al, 2007), 已有研究表明环境因子通过影响种子质量和元素 含量进而间接影响萌发性状(De Frenne et al, 2011; Wu et al, 2018)。此外, 不同种源地的种子对环境的 响应存在差异(Cochrane et al, 2015)。萌发率和初始
萌发时间是种子萌发过程的关键指标, 常用来表征 种子向幼苗过渡的潜力, 在自然更新进程中起重要 作用(Donohue, 2002; Rosbakh \& Poschlod, 2015)。种 子萌发性状的差异反映了不同物种对环境的不同 适应策略(Bu et al, 2008)。例如, 紫花针茅(Stipa purpurea) 可以通过延长萌发时间以避免种子集中萌发, 从而减弱种间的竞争作用, 增加幼苗的存活率 $(\mathrm{Li}$ et $\mathrm{al}, 2015$ ); 较早萌发的拟南芥 (Arabidopsis thaliana) 具有更长的营养生长时期, 繁殖个体更大, 种子产量也更高(Donohue, 2002)。

我国受第四纪冰川事件的影响较小, 古老子遗 植物丰富, 主要分布在亚热带山地(吴征镒, 1980; 沈泽昊等, 2000), 且大多存在幼苗更新障碍。在物 种分布区边缘, 植物对环境改变(如气候变暖)的响 应更为敏感, 因而在这些地区探究植物的更新状况 及成因, 对预测种群动态及物种保护具有更重要的 意义。秦岭山脉呈东西走向, 是我国南、北气候的 过渡带, 是我国生物多样性保护的重点和热点区域 (张百平, 2019), 也是我国亚热带气候区特有种分布 的北缘, 该区域是研究植物更新状况及其对环境响 应的天然试验场。

连香树(Cercidiphyllum japonicum)是连香树科 
连香树属落叶乔木, 属第三纪子遗植物、东亚植物 区系特有种, 多以散生单株或从生的克隆系生长于 海拔650-2,700 m的河岸、沟谷两侧(Kubo et al, 2004; 何东等, 2009)。连香树的果实为瞢荂果, 种子带翅, 主要依靠风力、水媒传播(Isagi et al, 2005), 以种子 和萌真繁殖为主。连香树在中国的分布区北缘位于 甘肃、陕西、河南、山西境内(图1)。在野外调查中, 我们只在甘肃天水市和陕西宁陕县发现有少量株 高低于 $5 \mathrm{~cm}$ 的连香树幼苗, 且种群都为大径级(胸 径大于 $20 \mathrm{~cm}$ ) 个体, 说明存在严重的幼苗更新限 制。然而, 导致连香树种群发生更新限制的原因并 不清楚。不同种源地连香树的种子性状有怎样的变 化? 影响种子萌发率的主要因子是什么? 连香树幼 苗更新限制是否发生在种子萌发阶段, 主要的原因 是什么? 本研究采集了中国分布区北缘(秦岭和太 行山脉) 5 个种源地的连香树种子, 试图通过比较不 同种源地间的种子性状以及不同温度下种子的萌 发性状来回答上述问题, 进而为该物种的保护提供 科学依据。

\section{材料与方法}

\section{1 研究区域概况}

研究区域位于秦岭-太行山脉 $\left(33.69^{\circ}-35.44^{\circ} \mathrm{N}\right.$, $\left.106.58^{\circ}-112.15^{\circ} \mathrm{E}\right)$, 涵盖了连香树在中国境内的北
缘分布区。该区域处于暖温带和北亚热带的过渡带, 降水季节性和突发性特点显著，主要集中在6-9月 (蒋冲等, 2013)。秦岭为我国南、北地理与气候分界 线，南坡以亚热带植被类型为主，北坡以温带成分 为主; 而太行山脉属暖温带大陆季风气候, 以暖温 带植被类型为主。连香树在该区域内主要以斑块状 或聚集分布在山地河岸带中(杨荣慧等, 2012), 所处 群落类型为落叶阔叶林, 群落优势树种为色木槭 (Acer mono)、领春木(Euptelea pleiospermum)、秦岭 梣(Fraxinus paxiana)、脱皮榆(Ulmus lamellosa)等。

\section{2 样品采集及性状测量}

2018年9-10月，采集连香树的成熟果实(浅黄 色)。在每个种群中至少采集3棵母树(胸径20-40 cm) 的果实, 共采集32份样品。去除土壤表层调落物, 采集0-20 cm土层土壤，混匀后用四分法留取500 g 左右, 在每个种源地至少采集3份土壤样品。因在济 源的连香树野生种群中只发现1株母树，并且种子 很少，故从该地区的人工林中采集种子。本研究中 属于秦岭的连香树种源地包括：甘肃省天水市(TS, 4 株)、陕西省宁陕县(NS, 8株)和河南省奕川县(LC, 3 株); 属于太行山脉的连香树种源地包括河南省济 源市(JY, 6株)和山西省沁水县(QS, 11株)。各个种源 地的环境因子见表1。样品带回实验室后置于干燥 阴凉处自然风干，待果实自然开裂后收集种子，从

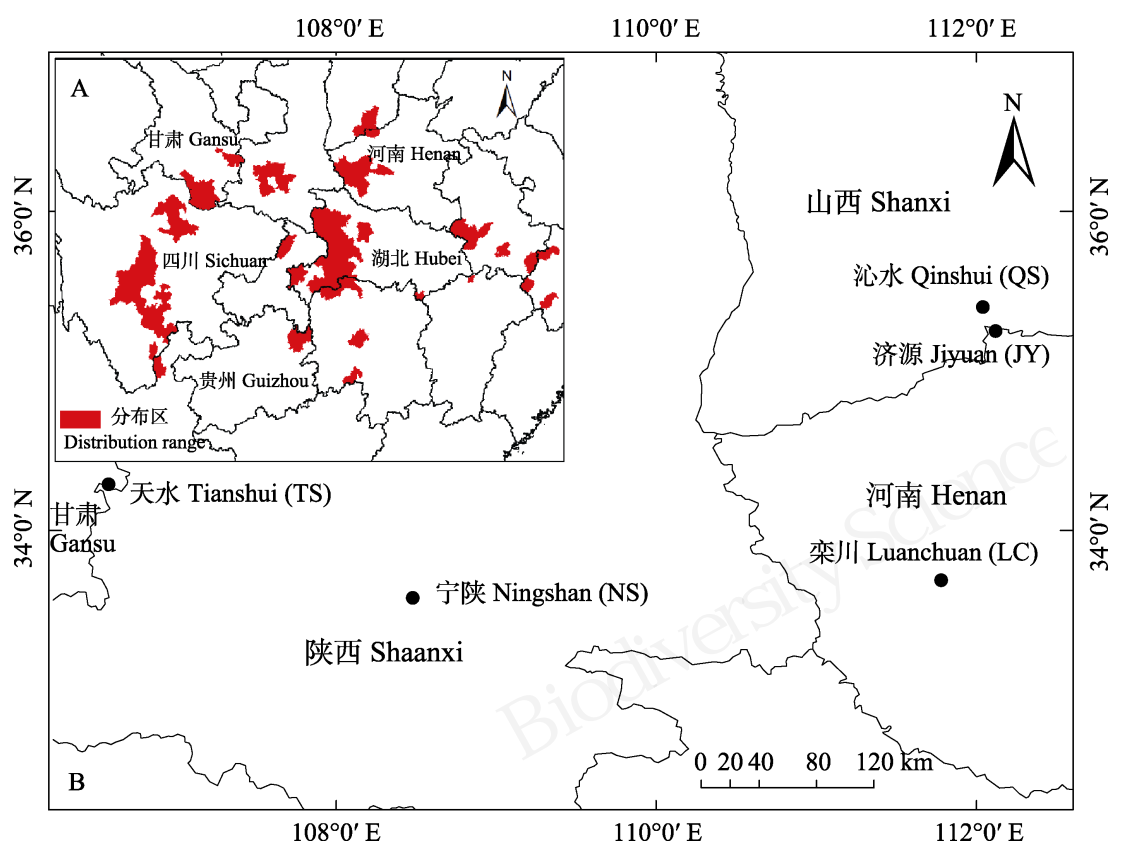

图1 连香树在中国境内的分布范围(A)及本研究样点位置(B)

Fig. 1 The distribution range of Cercidiphyllum japonicum in China (A) and site locations in this study (B) 
每份样品中随机选取适量种子用于观察是否有休 眠现象，其余种子在 $4^{\circ} \mathrm{C}$ 条件下冷藏保存。

随机选取适量种子(300 粒左右)用扫描仪 (CanoScan LiDE 220)进行扫描, 并用 Batch 软件计 算种子长度和宽度, 然后称取种子质量。选取适量 种子充分研磨, 称取适量样品(0.3 mg 左右), 利用 稳定同位素质谱仪(Isotope-MS, delta V advantage; ThermoFisher Scientific, Darmstadt, Germany)测定 种子中的碳和氮含量; 称取适量样品 (0.05 mg 左右) 加入消化管中, 加入 $3 \mathrm{~mL} \mathrm{HNO}_{3}$ 和 $2 \mathrm{~mL} \mathrm{H}_{2} \mathrm{O}_{2}$, 利 用微波消解仪(ETHOS ONE, Milestone, Italy)制成 溶液, 再利用电感耦合等离子体发射光谱仪 (IPC-OES) (Optima 8000, PerkinElmer, USA)测定种 子的磷含量。土壤元素含量与种子元素含量测定方 法相同。

\section{3 种子活力检测及萌发实验}

按照国际种子检验协会(ISTA)的检验规程, 采 用四唑(1.0\%)染色法测定种子活力，设置3个重复， 每份50粒种子, 染色 $24 \mathrm{~h}$ 后用显微镜观察种胚颜色, 呈粉红色即为有活力, 否则即为无活力。为检验存 咜时间长短是否影响种子活力，分别在2019年2月 和5月进行两次种子活力检测实验。为检验温度是 否对不同种源地种子萌发有影响, 于2019年4月开 展 4 个温度条件 $\left(10^{\circ} \mathrm{C} 、 15^{\circ} \mathrm{C} 、 20^{\circ} \mathrm{C} 、 25^{\circ} \mathrm{C}\right.$; 涵盖研 究区域内生长季温度范围, 附录1)下的种子萌发实 验, 3 个重复, 每份 50 粒种子。萌发实验前用 $1.0 \%$ 的
$\mathrm{NaClO}$ 溶液对种子消毒 $3 \mathrm{~min}$, 再用蒸馏水冲洗干净, 将种子均匀置于直径 $9 \mathrm{~cm}$ 的垫有用蒸馏水湿润滤 纸的培养血中，放于人工气候箱(QHX-300BSH-III, 上海)中, 分别设置光环境(13 h光照, $11 \mathrm{~h}$ 黑暗)、温 度条件 $\left(10^{\circ} \mathrm{C} 、 15^{\circ} \mathrm{C} 、 20^{\circ} \mathrm{C} 、 25^{\circ} \mathrm{C}\right)$ 。萌发开始后，每 $24 \mathrm{~h}$ 观察种子的萌发情况, 胚根长度超过 $1 \mathrm{~mm}$ 记为 萌发成功, 连续7天没有新萌发的种子时结束实验。 在进行萌发实验前，从每份种子样品中各选取适量 未经低温存咜的种子，参考上述方法在室温下观察 萌发情况，发现所有种源地的种子皆可萌发，表明 连香树种子无休眠现象。

\section{4 气候数据采集}

降水量和温度数据从 WorldClim 网站 (http://www. worldclim.org/)下载30'栅格数据(空间 分辨率为 $1 \mathrm{~km} \times 1 \mathrm{~km})$, 用ArcGIS 10.2提取年均温、 年降水量、月均温等气候数据。

\section{5 数据分析}

用ANOVA分析不同种群间的种子性状差异 $(P$ $<0.05)$; 用 $t$ 检验比较秦岭和太行山区的种子性状; 用Pearson相关分析检测地理因子(经度、纬度、海 拔)、环境因子(年均温、年降水量, 土壤碳、氮、磷 含量)和种子内在属性(种子大小、质量、活力, 种子 碳、氮、磷元素含量)以及种子萌发性状(萌发率、 萌发时间)间的相关关系 $(P<0.05)$ 。其中，5个种源地 的种子性状为各种源地内所有采样个体性状的平 均值; 太行山区和秦岭地区的种子性状为分布于太

表1 秦岭-太行山脉连香树 5 个种源地的位置及环境因子

Table 1 Locations and environmental factors of five provenances of Cercidiphyllum japonicum in Qinling-Taihang Mountains

\begin{tabular}{|c|c|c|c|c|c|}
\hline \multirow{2}{*}{$\begin{array}{l}\text { 环境因子 } \\
\text { Environmental factors }\end{array}$} & \multicolumn{3}{|c|}{ 秦岭 Qinling Mountains } & \multicolumn{2}{|c|}{ 太行山脉 Taihang Mountains } \\
\hline & $\begin{array}{l}\text { 天水 } \\
\text { Tianshui }\end{array}$ & $\begin{array}{l}\text { 宁陕 } \\
\text { Ningshan }\end{array}$ & $\begin{array}{l}\text { 奕川 } \\
\text { Luanchuan }\end{array}$ & $\begin{array}{l}\text { 沁水 } \\
\text { Qinshui }\end{array}$ & $\begin{array}{l}\text { 济源 } \\
\text { Jiyuan }\end{array}$ \\
\hline 纬度 Latitude & $34.29^{\circ} \mathrm{N}$ & $33.58^{\circ} \mathrm{N}$ & $33.69^{\circ} \mathrm{N}$ & $35.4^{\circ} \mathrm{N}$ & $35.25^{\circ} \mathrm{N}$ \\
\hline 经度 Longitude & $106.58^{\circ} \mathrm{E}$ & $108.48^{\circ} \mathrm{E}$ & $111.78^{\circ} \mathrm{E}$ & $112.04^{\circ} \mathrm{E}$ & $112.12^{\circ} \mathrm{E}$ \\
\hline 海拔 Altitude (m) & 1,592 & 1,741 & 1,478 & 1,392 & 589 \\
\hline 年均温 Annual mean temperature $\left({ }^{\circ} \mathrm{C}\right)$ & 8.8 & 8.2 & 8.5 & 7.1 & 11.6 \\
\hline 年降水量 Annual mean precipitation (mm) & 719 & 919 & 893 & 694 & 612 \\
\hline 土壤碳含量 Soil C content (\%) & 8.87 & 15.88 & 8.78 & 9.31 & 11.32 \\
\hline 土壤氮含量 Soil N content (\%) & 0.57 & 1.14 & 0.86 & 0.75 & 0.75 \\
\hline 土壤磷含量 Soil P content (mg/g) & 0.11 & 0.09 & 0.11 & 0.09 & 0.13 \\
\hline 9 月平均温 Mean monthly temperature in September $\left({ }^{\circ} \mathrm{C}\right)$ & 14 & 14 & 15 & 13 & 18 \\
\hline 10 月平均温 Mean monthly temperature in October $\left({ }^{\circ} \mathrm{C}\right)$ & 9 & 9 & 9 & 8 & 13 \\
\hline 11月平均温 Mean monthly temperature in November $\left({ }^{\circ} \mathrm{C}\right)$ & 3.2 & 3 & 3.3 & 1.4 & 5.3 \\
\hline 12 月平均温 Mean monthly temperature in December $\left({ }^{\circ} \mathrm{C}\right)$ & -1.9 & -1.7 & -2.2 & -5 & -0.9 \\
\hline
\end{tabular}


行和秦岭山脉的连香树个体性状的平均值。不同种 源地间种子萌发性状的比较为 4 个温度条件下对应 性状的平均值。

其中种子萌发指标计算公式如下:

萌发率 $=(\mathrm{N} / \mathrm{a}) \times 100 \%$

平均萌发时间 $(M G T)=\sum\left[\left(n_{t} \times t\right) / N\right]$

初始萌发时间 $\left(\mathrm{T}_{0}\right)=$ 种子萌发开始所需要的 天数

其中, $n_{t}$ 为第 $\mathrm{t}$ 日的当日萌发数量, $N$ 为最终萌发数量, $\mathrm{a}=50$ 。

\section{2 结果}

\section{1 不同种源间种子性状差异}

在中国分布区的北缘, 连香树种子性状的变异 系数范围为 $1.62 \%-57.97 \%$, 其中萌发率的变异系数
最大(表2)。咜存7个月的平均活力(15.31\%)比陉存4 个月的平均活力 (48.14\%)低32.83\% (表3)。

ANOVA结果显示，除种子质量、宽度、 $\mathrm{T}_{0}$ 和种 子碳含量外，种子长度、萌发率、平均萌发时间 (MGT)、氮和磷含量在不同种源间的差异均达到显 著水平(表2)。多重比较的结果如表3所示: 天水、 宁陕、奕川和沁水种群的种子长度和宽度均无显著 差异, 均显著大于济源的种子长度和宽度; 济源与 栾川的种子宽度无显著差异; 天水与宁陕和沁水的 种子萌发率无显著差异，但都显著高于济源和奕川; 奕川的萌发率显著低于其他种源地; 栾川的MGT 最短，显著小于其他种源地; 天水、宁陕、沁水和 济源的MGT无显著差异; 咜存 4 个月后，奕川与宁 陕和沁水的种子活力无显著差异，却显著低于天水 和济源; 咜存 7 个月后所有种源地的种子活力都下

表2 中国分布区北缘连香树种子性状变异

Table 2 Seed trait variations of Cercidiphyllum japonicum in north marginal distribution in China

\begin{tabular}{|c|c|c|c|c|c|c|c|}
\hline 种子性状 Seed traits & 平均值 Mean & 最大值 Max. & 最小值 Min. & 变异系数 Coefficient of variation (\%) & $d f$ & $F$ & $P$ \\
\hline 种子质量 Seed mass (mg) & 0.56 & 0.67 & 0.52 & 11.04 & 4 & 0.46 & 0.678 \\
\hline 种子长度 Seed length $(\mathrm{cm})$ & 0.52 & 0.58 & 0.41 & 12.66 & 4 & 6.53 & $<0.001$ \\
\hline 种子宽度 Seed width (cm) & 0.26 & 0.28 & 0.23 & 7.45 & 4 & 40.36 & 0.074 \\
\hline 种子萌发率 Germination percentage (\%) & 14.40 & 21.77 & 1.38 & 57.97 & 4 & 22.07 & $<0.001$ \\
\hline $\begin{array}{l}\text { 初始萌发时间 Days of the first } \\
\text { germination record (d) }\end{array}$ & 4.48 & 5.59 & 2.33 & 27.93 & 4 & 8.14 & 0.206 \\
\hline 平均萌发时间 Mean germination time (d) & 7.46 & 11.12 & 3.47 & 37.31 & 4 & 31.32 & $<0.001$ \\
\hline 种子碳含量 Seed C content (\%) & 44.50 & 45.51 & 43.82 & 1.62 & 4 & 2.33 & 0.081 \\
\hline 种子氮含量 Seed N content (\%) & 1.22 & 1.41 & 0.85 & 18.66 & 4 & 3.36 & $<0.05$ \\
\hline 种子磷含量 Seed P content (mg/g) & 2.13 & 3.23 & 1.09 & 37.84 & 4 & 7.97 & $<0.001$ \\
\hline
\end{tabular}

表3 中国分布区北缘5个种源地间连香树种子性状比较

Table 3 Seed traits of Cercidiphyllum japonicum from five provenances in north marginal distribution in China

\begin{tabular}{llllll}
\hline 种子性状 & 天水 & 宁陕 & 栾川 & 沁水 & 济源 \\
Seed traits & Tianshui (TS) & Ningshan (NS) & Luanchuan (LC) \\
Qinshui (QS) & Jiyuan (JY) \\
\hline 种子质量 Seed mass (mg) & $0.67 \pm 0.05^{\mathrm{a}}$ & $0.57 \pm 0.04^{\mathrm{a}}$ & $0.53 \pm 0.12^{\mathrm{a}}$ & $0.52 \pm 0.09^{\mathrm{a}}$ & $0.53 \pm 0.05^{\mathrm{a}}$ \\
种子长度 Seed length (cm) & $0.55 \pm 0.02^{\mathrm{a}}$ & $0.57 \pm 0.03^{\mathrm{a}}$ & $0.52 \pm 0.07^{\mathrm{a}}$ & $0.56 \pm 0.02^{\mathrm{a}}$ & $0.41 \pm 0.02^{\mathrm{b}}$ \\
种子宽度 Seed width (cm) & $0.27 \pm 0.01^{\mathrm{a}}$ & $0.28 \pm 0.01^{\mathrm{a}}$ & $0.26 \pm 0.04^{\mathrm{ab}}$ & $0.27 \pm 0.01^{\mathrm{a}}$ & $0.23 \pm 0.01^{\mathrm{b}}$ \\
萌发率 Germination percentage (\%) & $21.77 \pm 1.62^{\mathrm{a}}$ & $18.03 \pm 2.07^{\mathrm{a}}$ & $1.38 \pm 0.37^{\mathrm{c}}$ & $19.86 \pm 1.80^{\mathrm{a}}$ & $10.95 \pm 0.91^{\mathrm{b}}$ \\
初始萌发时间 Days of the first germination record (d) & $5.59 \pm 0.55$ & $4.75 \pm 0.26$ & $2.33 \pm 0.55$ & $4.73 \pm 0.28$ & $5.01 \pm 0.31$ \\
平均萌发时间 Mean germination time (d) & $11.12 \pm 0.63^{\mathrm{a}}$ & $6.54 \pm 0.72^{\mathrm{a}}$ & $3.47 \pm 0.64^{\mathrm{b}}$ & $8.25 \pm 0.32^{\mathrm{a}}$ & $7.94 \pm 0.32^{\mathrm{a}}$ \\
贮存4个月种子活力 Vitality of seeds stored for 4 months (\%) & $54.83 \pm 3.85^{\mathrm{a}}$ & $49.25 \pm 5.23^{\mathrm{ab}}$ & $37.33 \pm 7.07^{\mathrm{b}}$ & $47.09 \pm 2.22^{\mathrm{ab}}$ & $52.22 \pm 2.85^{\mathrm{a}}$ \\
拒存7个月种子活力 Vitality of seeds stored for 7 months (\%) & $26.83 \pm 8.28^{\mathrm{a}}$ & $15.67 \pm 6.92^{\mathrm{ab}}$ & $1.11 \pm 0.59^{\mathrm{b}}$ & $11.82 \pm 3.38^{\mathrm{ab}}$ & $21.11 \pm 4.07^{\mathrm{ab}}$ \\
种子碳含量 Seed C content (\%) & $44.22 \pm 0.59^{\mathrm{ab}}$ & $43.96 \pm 0.48^{\mathrm{b}}$ & $43.82 \pm 0.18^{\mathrm{b}}$ & $44.97 \pm 0.36^{\mathrm{ab}}$ & $45.51 \pm 0.34^{\mathrm{b}}$ \\
种子氮含量 Seed N content (\%) & $1.39 \pm 0.1^{\mathrm{a}}$ & $1.26 \pm 0.09^{\mathrm{a}}$ & $0.85 \pm 0.08^{\mathrm{b}}$ & $1.17 \pm 0.08^{\mathrm{a}}$ & $1.41 \pm 0.09^{\mathrm{a}}$ \\
种子磷含量 Seed P content (mg/g) & $2.51 \pm 0.37^{\mathrm{ab}}$ & $2.11 \pm 0.28^{\mathrm{bc}}$ & $1.09 \pm 0.18^{\mathrm{d}}$ & $1.72 \pm 0.18^{\mathrm{cd}}$ & $3.23 \pm 0.19^{\mathrm{a}}$ \\
\hline
\end{tabular}

同一行内不同字母表示在0.05水平差异显著。Different lowercase letters indicate significant differences at $P=0.05$ level. 
表4 秦岭和太行山脉间连香树种子性状比较

Table 4 Comparisons of seed traits of Cercidiphyllum japonicum in Qinling and Taihang mountains

\begin{tabular}{llllll}
\hline $\begin{array}{l}\text { 种子性状 } \\
\text { Seed traits }\end{array}$ & $\begin{array}{l}\text { 秦岭山脉 } \\
\text { Qinling Mountains }\end{array}$ & $\begin{array}{l}\text { 太行山脉 } \\
\text { Taihang Mountains }\end{array}$ & $\begin{array}{l}\text { 自由度 } \\
\text { df }\end{array}$ & $t$ & $P$ \\
\hline 种子质量 Seed mass (mg) & $0.58 \pm 0.03$ & $0.52 \pm 0.06$ & 30 & 0.77 & 0.447 \\
种子长度 Seed length (cm) & $0.56 \pm 0.02$ & $0.51 \pm 0.02$ & 30 & 1.8 & 0.08 \\
种子宽度 Seed width (cm) & $0.27 \pm 0.01$ & $0.25 \pm 0.01$ & 30 & 1.57 & 0.13 \\
萌发率 Germination percentage (\%) & $16.48 \pm 1.31$ & $14.67 \pm 0.98$ & 30 & 1.1 & 0.273 \\
初始萌发时间 Days of the first germination record (d) & $4.87 \pm 0.27$ & $4.89 \pm 0.21$ & 30 & -0.09 & 0.931 \\
平均萌发时间 Mean germination time (d) & $8.68 \pm 0.33$ & $8.07 \pm 0.23$ & 30 & 1.57 & 0.118 \\
种子碳含量 Seed C content (\%) & $44.00 \pm 0.29$ & $45.16 \pm 0.27$ & 30 & -2.96 & $<0.01$ \\
种子氮含量 Seed N content (\%) & $1.22 \pm 0.07$ & $1.26 \pm 0.06$ & 30 & -0.42 & 0.678 \\
种子磷含量 Seed P content (mg/g) & $2.01 \pm 0.22$ & $2.25 \pm 0.22$ & 30 & -0.78 & 0.443 \\
\hline
\end{tabular}
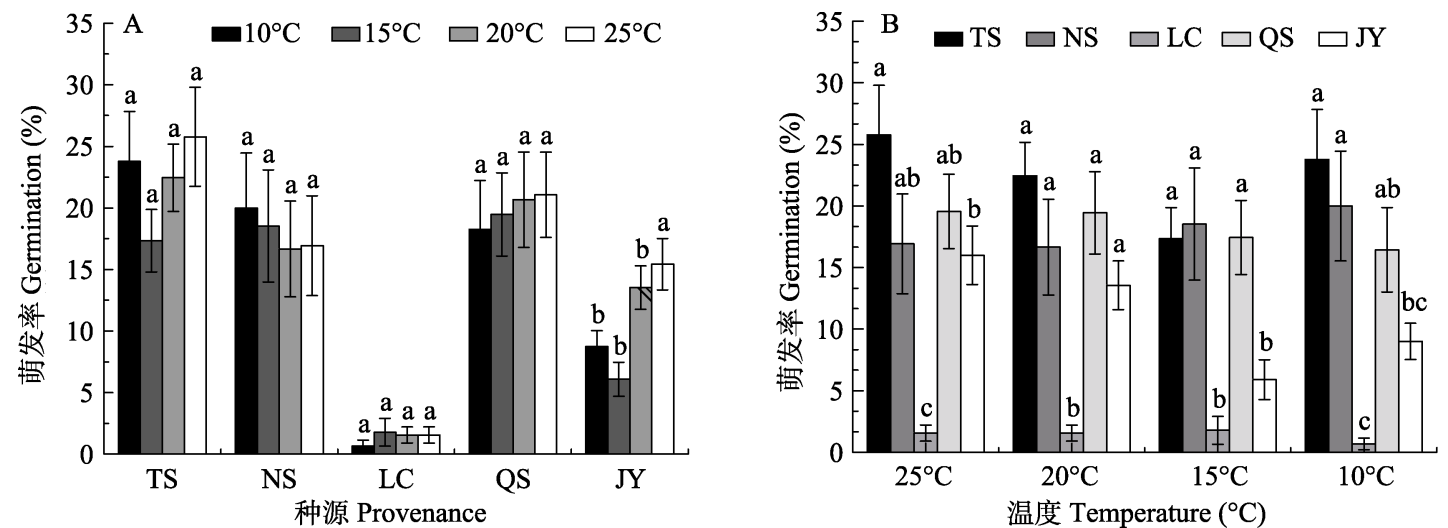

图2 连香树种子萌发率(平均值 \pm 标准误)比较。(A)同一种源地不同温度条件; (B)同一温度条件下 5 个种源地。TS: 天水; NS: 宁陕; LC: 栾川; QS: 沁水; JY, 济源。误差棒上不同字母表示有显著差异 $(P<0.05)$ 。

Fig. 2 Comparisons of seed germination percentage (mean \pm SE) in Cercidiphyllum japonicum. (A) Seed germination percentage at different temperatures in the same provenance; (B) Seed germination percentage among five provenances at the same temperature. TS, Tianshui; NS, Ningshan; LC, Luanchuan; QS, Qinshui; JY, Jiyuan. Bars with different lowercase letters indicate significant differences $(P<0.05)$.

降明显, 且橸川的种子活力下降最多, 天水的种子 活力下降最少; 济源与天水和沁水的种子碳含量无 显著差异, 却显著高于宁陕和森川; 橸川的种子氮 含量显著低于其他种源地; 奕川与沈水的种子磷含 量无显著差异, 却显著低于其他种源地; 济源与天 水的种子磷含量无显著差异, 却显著高于宁陕、榇 川和沁水; 宁陕与沁水的种子磷含量无显著差异。

$t$ 检验结果表明: 太行山区连香树的种子碳含 量高于秦岭山区, 而其他种子性状在秦岭和太行山 区间无显著差异(表4)。

\section{2 不同温度条件下连香树种子萌发性状}

萌发率ANOVA结果表明: 天水、宁陕、奕川和 沁水种群各自的种子萌发率在 4 个温度条件下均无 显著差异, 而济源的萌发率在 $25^{\circ} \mathrm{C}$ 条件下显著高于 $10^{\circ} \mathrm{C} 、 15^{\circ} \mathrm{C} 、 20^{\circ} \mathrm{C}$ 条件下 (图 $2 \mathrm{~A}$ )。在 $25^{\circ} \mathrm{C}$ 和 $20^{\circ} \mathrm{C}$ 的
萌发条件下，奕川的萌发率都显著低于其他 4 个种 源地; 在 $15^{\circ} \mathrm{C}$ 条件下, 奕川与济源的种子萌发率无 显著差异，但均显著低于天水、宁陕和沁水; 在 $10^{\circ} \mathrm{C}$ 的萌发条件下, 奕川与济源的萌发率无显著差 异, 却显著低于天水、宁陕和沁水; 在 $10^{\circ} \mathrm{C}$ 的条件 下, 济源与沁水间的萌发率无显著差异, 但济源的 萌发率显著低于天水和宁陕的萌发率(图2B)。

MGT的ANOVA结果显示: 在 $25^{\circ} \mathrm{C}$ 条件下, 天 水种群的MGT长于 $10^{\circ} \mathrm{C} 、 15^{\circ} \mathrm{C} 、 20^{\circ} \mathrm{C}$ 条件下; 宁陕 和沁水的MGT在 4 个温度条件下无显著差异; 在 $20^{\circ} \mathrm{C}$ 条件下, 栾川的MGT显著大于其他 3 个温度条 件下; 在 $15^{\circ} \mathrm{C}$ 条件下, 济源的MGT显著短于 $20^{\circ} \mathrm{C}$ 和 $25^{\circ} \mathrm{C}$ 条件下, 而与 $10^{\circ} \mathrm{C}$ 条件下无显著差异(图3)。在 $15^{\circ} \mathrm{C}$ 条件下天水种群的 $\mathrm{T}_{0}$ 最长, $10^{\circ} \mathrm{C}$ 条件下的 $\mathrm{T}_{0}$ 大 于 $20^{\circ} \mathrm{C}$ 和 $25^{\circ} \mathrm{C}$ 条件下, 而在 $20^{\circ} \mathrm{C}$ 和 $25^{\circ} \mathrm{C}$ 条件下无显 

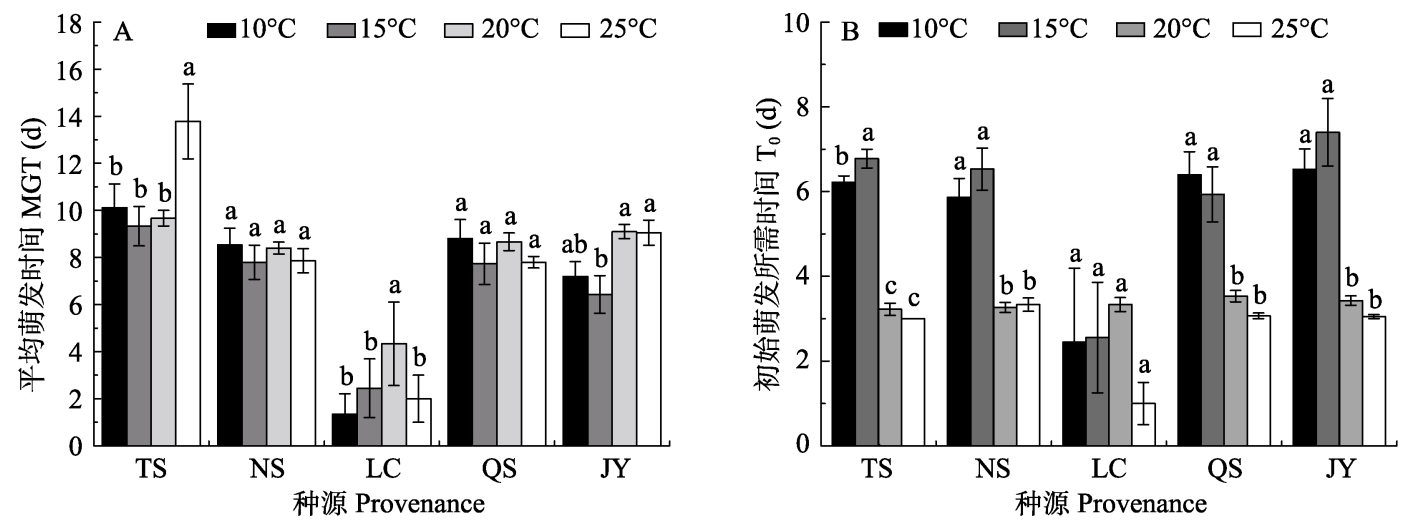

图3 不同温度条件下连香树种子萌发时间比较。TS: 天水; NS: 宁陕; LC: 栾川; QS: 沁水; JY, 济源。误差棒上不同字母 表示有显著差异 $(P<\mathbf{0 . 0 5})$ 。

Fig. 3 Comparisons of seed germination time at different temperatures. TS, Tianshui; NS, Ningshan; LC, Luanchuan; QS, Qinshui; JY, Jiyuan. $\mathrm{T}_{0}$, Days of the first germination record. Bars with different lowercase letters indicate significant differences $(P<0.05)$.

表5 种子性状间的相关关系(对角线左下为 $P$ 值, 右上为 $r$ 值)

Table 5 Correlations among seed traits (The lower left section below the diagonal are $P$ values and the upper right section are $r$ values)

\begin{tabular}{|c|c|c|c|c|c|c|c|c|}
\hline $\begin{array}{l}\text { 种子性状 } \\
\text { Seed traits }\end{array}$ & $\begin{array}{l}\text { 种子质量 } \\
\text { Seed } \\
\text { mass }\end{array}$ & $\begin{array}{l}\text { 种子长度 } \\
\text { Seed } \\
\text { length }\end{array}$ & $\begin{array}{l}\text { 种子宽度 } \\
\text { Seed } \\
\text { width }\end{array}$ & $\begin{array}{l}\text { 萌发率 } \\
\text { Germination } \\
\text { percentage }\end{array}$ & $\begin{array}{l}\text { 贮存7个月 } \\
\text { 种子活力 } \\
\text { Vitality of } \\
\text { seeds stored } \\
\text { for } 7 \text { months }\end{array}$ & $\begin{array}{l}\text { 种子碳含量 } \\
\text { Seed C } \\
\text { content }\end{array}$ & $\begin{array}{l}\text { 种子氮含量 } \\
\text { Seed N } \\
\text { content }\end{array}$ & $\begin{array}{l}\text { 种子磷含量 } \\
\text { Seed P } \\
\text { content }\end{array}$ \\
\hline 种子质量 Seed mass & - & 0.579 & 0.678 & 0.797 & $0.398^{*}$ & -0.484 & 0.331 & 0.019 \\
\hline 种子长度 Seed length & 0.306 & - & $0.970^{* *}$ & 0.224 & 0.159 & -0.743 & -0.332 & -0.677 \\
\hline 种子宽度 Seed width & 0.209 & 0.006 & - & 0.422 & 0.183 & -0.846 & -0.248 & -0.579 \\
\hline 萌发率 Germination percentage & 0.106 & 0.717 & 0.479 & - & $0.718^{* *}$ & -0.391 & 0.603 & 0.423 \\
\hline $\begin{array}{l}\text { 咜存7个月种子活力 Vitality of seeds } \\
\text { stored for } 7 \text { months }\end{array}$ & 0.024 & 0.385 & 0.316 & 0.001 & - & 0.298 & $0.683^{* *}$ & $0.461^{*}$ \\
\hline 种子碳含量 Seed C content & 0.409 & 0.150 & 0.071 & 0.515 & 0.097 & - & $0.559^{* *}$ & $0.410^{*}$ \\
\hline 种子氮含量 Seed N content & 0.587 & 0.586 & 0.687 & 0.282 & 0.001 & 0.001 & - & $0.796^{* *}$ \\
\hline 种子磷含量 Seed P content & 0.975 & 0.210 & 0.306 & 0.478 & 0.008 & 0.02 & 0.001 & - \\
\hline
\end{tabular}

$* * P<0.01 ; * P<0.05$

著差异(图3); 在 $10^{\circ} \mathrm{C}$ 和 $15^{\circ} \mathrm{C}$ 条件下，宁陕的 $\mathrm{T}_{0}$ 最长 且这两个温度条件下无显著差异，在 $20^{\circ} \mathrm{C}$ 和 $25^{\circ} \mathrm{C}$ 条 件下最短，都显著低于 $10^{\circ} \mathrm{C}$ 和 $15^{\circ} \mathrm{C}$ 条件下(图3)。在 4 个温度条件下, 栾川的 $\mathrm{T}_{0}$ 无显著差异(图3)。在 $20^{\circ} \mathrm{C}$ 和 $25^{\circ} \mathrm{C}$ 条件下, 沁水的 $\mathrm{T}_{0}$ 无显著差异, 却显著短于 $10^{\circ} \mathrm{C}$ 和 $15^{\circ} \mathrm{C}$ 条件下(图3)。济源的 $\mathrm{T}_{0}$ 在 $10^{\circ} \mathrm{C}$ 和 $15^{\circ} \mathrm{C}$ 条 件下无显著差异, 却显著长于 $20^{\circ} \mathrm{C}$ 和 $25^{\circ} \mathrm{C}$ 条件下 (图3)。

\section{3 种子性状间及种子性状与地理、气候因子间的} 相关关系

相关分析结果表明, 种子的长度和宽度显著正 相关, 萌发率与种子活力显著正相关, 种子活力与 种子质量、种子氮和磷含量显著正相关(表5)。

种子性状与地理、气候因子间关系如表6所示:
纬度与种子碳含量显著正相关; 经度与种子质量和 萌发率显著负相关，从西到东种子质量和萌发率都 呈下降的趋势; 海拔与种子长度和宽度显著正相关; 年均温与种子长度显著负相关; 年降水量与种子碳 含量显著负相关; 种子活力、氮含量和磷含量与环 境因子间无显著的相关关系。

\section{3 讨论}

3.1 中国分布区北缘连香树种子性状变异及成因 植物表型性状变异是基因和环境因子共同作 用的结果(刘志龙等, 2011; Sudrajat, 2016)。在中国 分布区的北缘(秦岭和太行山脉), 连香树种子性状 的平均变异系数为 $23.61 \%$, 高于川西云杉(Picea balfouriana) (15.96\%，幸云杰等，2009)、厚朴 
表6 种子性状与环境因子间Pearson相关性系数 $(r)$

Table 6 Pearson correlation coefficients $(r)$ between seed traits and environmental factors

\begin{tabular}{|c|c|c|c|c|c|c|c|c|}
\hline $\begin{array}{l}\text { 种子性状 } \\
\text { Seed traits }\end{array}$ & $\begin{array}{l}\text { 纬度 } \\
\text { Latitude }\end{array}$ & $\begin{array}{l}\text { 经度 } \\
\text { Longitude }\end{array}$ & $\begin{array}{l}\text { 海拔 } \\
\text { Altitude }\end{array}$ & $\begin{array}{l}\text { 年均降水量 } \\
\text { Annual mean } \\
\text { precipitation }\end{array}$ & $\begin{array}{l}\text { 年均温度 } \\
\text { Annual mean } \\
\text { temperature }\end{array}$ & $\begin{array}{l}\text { 土壤碳含量 } \\
\text { Soil C } \\
\text { content }\end{array}$ & $\begin{array}{l}\text { 土壤氮含量 } \\
\text { Soil N } \\
\text { content }\end{array}$ & $\begin{array}{l}\text { 土壤磷含量 } \\
\text { Sooil P } \\
\text { content }\end{array}$ \\
\hline 种子质量 Seed mass & -0.373 & $-0.957^{*}$ & 0.612 & 0.172 & -0.347 & -0.002 & -0.131 & -0.199 \\
\hline 种子长度 Seed length & -0.499 & -0.497 & $0.985^{* *}$ & 0.639 & $-0.925^{*}$ & -0.087 & 0.126 & 0.748 \\
\hline 种子宽度 Seed width & -0.588 & -0.657 & $0.982^{* *}$ & 0.643 & -0.832 & 0.000 & 0.152 & -0.852 \\
\hline 萌发率 Germination percentage & -0.442 & $-0.938^{*}$ & 0.269 & 0.157 & 0.128 & 0.511 & 0.248 & 0.067 \\
\hline $\begin{array}{l}\text { 初始萌发时间 Days of the first } \\
\text { germination record }\end{array}$ & 0.584 & -0.068 & -0.287 & -0.520 & 0.136 & 0.022 & -0.189 & -0.737 \\
\hline 平均萌发时间 Mean germination time & 0.284 & -0.670 & -0.146 & -0.543 & 0.272 & -0.048 & -0.412 & 0.155 \\
\hline $\begin{array}{l}\text { 贮存7个月种子活力 Vitality of seeds } \\
\text { stored for } 7 \text { months }\end{array}$ & 0.561 & 0.300 & -0.265 & -0.566 & 0.402 & 0.065 & -0.320 & 0.274 \\
\hline 种子碳含量 Seed C content & $0.928^{*}$ & 0.528 & -0.863 & $-0.906^{*}$ & 0.534 & -0.444 & -0.324 & -0.516 \\
\hline 种子氮含量 Seed N content & 0.402 & -0.416 & -0.330 & -0.728 & 0.459 & 0.037 & -0.127 & -0.254 \\
\hline 种子磷含量 Seed P content & 0.441 & -0.178 & -0.625 & -0.758 & 0.761 & 0.325 & 0.228 & -0.168 \\
\hline
\end{tabular}

$* * P<0.01 ; * P<0.05$.

(Magnolia officinalis) (4.35\%, 杨志玲等, 2009)、青 钱柳 (Cyclocarya paliurus) (20.53\%, 余诚棋等, 2009)、无患子(Sapindus mukurossi) (7.34\%, ᄀ松锋 等, 2014)、浙江楠(Phoebe chekiangensis) (16.99\%, 李因刚等, 2014)、枫香树(Liquidambar formosana) (15.83\%, 何庆海等, 2018)、领春木(Euptelea pleiospermum) (20.52\%, Wu et al, 2018)等。连香树为䧳雄 异株植物, 决定了其基因交流只能发生在不同植株 间, 可能增大种群内遗传变异发生的概率。另外, 该物种的分布范围较小, 零星分布于互不相连的小 区域中(王静等, 2010), 且秦岭-太行山区地形复杂, 地理隔离作用较强, 加之连香树花粉传播距离短 (袁丽洁等, 2007), 种群间存在基因交流障碍, 基于 分子标记的研究已证实连香树种群间遗传分化程 度高(王静等, 2010), 导致种群间性状变异较大。

在连香树的种子性状中, 萌发率的变异系数最 大, 且初始萌发时间和平均萌发时间的变异系数都 高于性状的平均变异系数, 表明连香树的种子萌发 性状在种群间有较大的差异。本研究发现萌发率仅 与种子活力显著相关, 而种子活力与种子自身属性 (质量、氮和磷含量) 密切相关。以往的研究发现种 子氮和磷含量与萌发率显著正相关, 却并未测定种 子活力(De Frenne et al, 2011; Soriano et al, 2011; Wu et al, 2018)。种子营养元素的高低决定种子生理功 能的强弱(Caliskan \& Makineci, 2020), 氮和磷元素 是代谢过程中酶和三磷酸腺苷(ATP)的重要成分,
较高的氮、磷含量有利于种子启动萌发(Fait et al, 2006; Soriano et al, 2011)。另外, 已有研究表明种子 中氮含量越高, 对水分的吸收效率也越高, 从而更 有利于萌发(Bedi et al, 2009)。本研究发现奕川种群 的种子氮和磷含量最低且种子活力下降最快, 因此 其种子萌发率最低。种子中的氮和磷含量与光照时 间、土壤中可利用元素的含量以及植物对元素的分 配策略有关(Groom \& Lamont, 2010; De Frenne et al, 2011; 田大栓, 2018)。例如当光资源受限时, 植物倾 向于把氮和磷元素更多地运输到叶片, 通过增加光 合速率来维持个体的生长(Evans, 1989)。在奕川, 连 香树生长于狭窄的沟谷中, 附近陡峭的石壁对太阳 的直射光有一定阻挡作用, 因而该地区分布的连香 树可能向叶片中分配更多的营养元素从而增加光 合速率, 以快速生长的策略来维持个体的生长和存 活。同时, 奕川种群种子的平均萌发时间短, 种子 活力下降最快, 快速萌发是该地区种子的萌发策略。

另外，不同种源间繁殖性状的差异也受种源间 遗传变异的影响(王荣芳等, 2008), 这些遗传变异往 往是植物在不同环境下长期适应的过程中形成的 (刘志龙等, 2011; 刘会良等, 2012)。连香树分布在山 地河岸带中, 靠近河边的连香树个体受夏季洪水的 扰动较大, 而离河岸较远的个体受季节性降水的扰 动较小。本研究中, 连香树种子萌发性状受温度的 影响较小, 而不同种源地季节性降水的差异可能是 种子萌发性状出现较大变异的另一原因。可见, 连 
香树种子萌发性状呈现较高的变异是其自身属性 (种子质量、氮和磷含量)、生境特征和地理隔离等 共同作用的结果。

本研究中, 连香树种子质量和萌发率在经度上 有显著的变化格局，与高山松(Pinus densata)、青海 云杉(Picea crassifolia)等植物在经度上的变化格局 相同(毛建丰等, 2007; 王娅丽, 2008), 而与经度梯 度上领春木(Euptelea pleiospermum)的萌发率格局 不同(Wu et al, 2018)。在中国分布区内, 领春木的种 子性状受温度的影响更大, 年均温通过影响种子质 量间接影响萌发率(Wu et al, 2018)。而本研究发现 连香树的种子质量、氮和磷含量通过影响种子活力 间接影响萌发率。本研究区域主要位于呈东西走向 的秦岭山脉, 经度跨度 $\left(5.54^{\circ}\right)$ 大于纬度跨度 $\left(1.82^{\circ}\right)$, 因而经度梯度上环境因子的差异可能是性状变异 的主要驱动因子。然而, 年降水量、年均温和土壤 因子等单一环境因子与连香树的种子质量和萌发 率并无显著的相关关系, 说明本研究中采用的环境 因子不是主要的影响因子。连香树生长的山地河岸 带受季节性降水的影响较大, 推测季节性降水的变 化可能是主要的影响因子。另外, 光照时间的长短 影响光合作用过程和碳水化合物的积累, 不同种源 地间光照时间长短也会影响种子性状。在未来的研 究中应考虑气候的季节性差异以及光照时间长短 的作用。

\section{2 影响连香树种子萌发和种群更新的主要原因}

种子萌发率由种子活力和萌发条件共同决定 (Ma et al, 2016), 任何一个条件不满足都会导致植 物发生更新障碍(Hooper et al, 2005; 朱教君等, 2007; 贺一鸣等, 2017)。在中国分布区的北缘, 连香 树的种子萌发率均很低(平均萌发率为 $14.4 \%$ ), 萌 发率最高的天水也仅有 $21.77 \%$, 这与冯朝元(2012) 和陈学龙等(2017)的研究结果相似, 表明萌发率低 是连香树的物种特性之一。本研究发现种子自身属 性通过影响种子活力间接影响萌发率。连香树种子 质量较小、营养物质含量较低是导致其种子萌发率 低的主要原因。种子具有较低的萌发率的特性是限 制连香树幼苗更新的主要原因之一。

种群的更新还受到光照、水分、温度、人为砍 伐、土壤基质以及植物自身特性的影响(蔵润国等, 1999; Masaki et al, 2007; Han et al, 2018)。种子品质
对种子萌发和种群更新有重要影响 (Susko \& Lovett-Doust, 2000), 而种子活力是评估种子品质的 重要指标之一(赖江山等，2003; Bu et al，2007; Shaban, 2013)。本研究发现种子萌发率主要受种子 活力的影响。李文良等(2008)和冯朝元(2012)发现连 香树的种子活力低于 $30 \%$, 本研究中连香树的种子 活力略高(48.14\%), 这可能是由于不同种源地的生 境差异和繁殖策略的不同。局部地区环境资源的差 异影响植物生长和繁殖的权衡策略, 进而造成植物 繁殖投入的差异(Villellas \& García, 2013)。在物种分 布区的边缘，环境对气候变化更为敏感，种子繁殖 更利于植物应对环境的改变(Dang et al, 2010; Wei et al, 2015)。在中国分布区的北缘，高活力的种子才 利于连香树种群的更新与维持, 这是边缘分布种群 对特有生境的适应策略。另外, 本研究发现连香树 种子不耐咜存, 通过比较咜存 7 个月(约等于种子成 熟到第二年春天的时间间隔)与咜存 4 个月的种子, 发现超过 $70 \%$ 的种子丧失活力。结合连香树的生境 特征(季节性洪水), 即使有少量种子完成萌发过程, 在夏季洪水的干扰下也很难存活。在野外调查中, 虽然在天水和宁陕发现有少量幼苗生长于裸露的 土壤基质上，却没有发现幼树。与在日本开展的研 究结果相似, 即只在无调落物覆盖的土壤或腐烂的 枯倒木上发现有连香树幼苗(Sakio et al, 2002; Masaki et al, 2007)。连香树种子质量小, 种子中储 备的营养物质较少，林下的落叶层阻碍刚形成的幼 苗在短时间内接触到土壤而导致其死亡(Kubo et al, 2004)。Masaki等(2007)认为连香树成功从种子向幼 苗的过渡过程就如同中彩票(winning a 'lottery')一 样, 是偶然事件。连香树种子活力下降快, 且生境 地特性是造成连香树更新障碍的另一主要原因。

本研究的预实验表明连香树种子无休眠现象。 不同温度条件下，除济源连香树人工林中的种子萌 发率有较小的差异外, 其他种源地的种子萌发率在 不同温度下并无差异，表明连香树种子适宜萌发的 温度范围较广(熊丹等, 2007; 李文良等, 2008)。在 中国分布区北缘，9-10月平均温度在 $10^{\circ} \mathrm{C}$ 左右，该 温度是连香树种子萌发的适宜温度。研究区域内, 连香树种子的平均初始萌发时间为 $4.48 \mathrm{~d}$, 平均萌 发时间为 $7.46 \mathrm{~d}$, 说明连香树具有低温萌发和快速 萌发的物种特性。由于河岸带生境水分相对充足, 生境地晚秋和初冬时期的温度条件适宜连香树种 
子萌发。当年成熟的种子散落到林下后, 有活力的 种子在短时间内就可以完成萌发过程, 并在适宜的 基质上会有少量幼苗成功定植，但幼苗只有短暂的 生长周期 $\left(11\right.$ 月的温度低于 $\left.5^{\circ} \mathrm{C}\right)$, 这样的幼苗在冬季 低温条件下不能存活。连香树种群更新障碍现象与 “枫香林下没枫香” (王传华等，2011)的问题相似, 种子无休眠以及低温的萌发特性是种群更新障碍 的第三个主要原因。

\section{3 连香树天然种群保护的建议与展望}

连香树是亚热带山地河岸带特有的珍稀木本 植物, 对该区域物种保护以及物种保护成效的评估 有重要的指示意义。本研究证实种子萌发是连香树 幼苗更新限制的主要阶段, 这是由该物种的种子特 性(萌发率低、种子活力下降快、种子无休眠和低温 萌发)决定的。种子繁殖是物种在分布区边缘应对环 境变化最有效的方式, 种子萌发限制中国分布区北 缘连香树种群的幼苗更新, 随着老龄个体的死亡, 该物种在局域尺度上的灭绝风险将极大增加。本研 究中的连香树种群几乎都位于自然保护区内, 但只 在甘肃天水和陕西宁陕发现有少量幼苗, 表明当前 对该物种的保护工作还远远不够。特别是河南栾川 的连香树种群, 由于其种子品质最差(氮和磷含量 低且最不耐咜存)导致其萌发率极低, 该地区连香 树种群存在严重的更新障碍, 面临的灭绝风险也更 高, 因此应该加大保护力度。同时, 我们发现天水 的种子萌发率最高也最耐伧存，该地区的种质资源 有利于人工育苗, 也最具有保护价值。由于连香树 的种子自身属性和生境地特性限制其幼苗自然更 新, 因此从最优的种源地(比如天水)采集种子, 人 工育苗后进行移栽是保护该物种最有效的方式。当 前, 在河南济源、陕西宁陕和四川茂县开展的人工 抚育工作已卓有成效。在未来的研究工作中，应该 开展同质园实验并监测不同生活史阶段的生长状 况, 选育出最具更新潜力的种源, 进而更好地服务 于该物种以及该区域物种的保护工作。

致谢: 感谢山西历山国家级自然保护区、河南济源 市林业局、河南栾川县龙峪湾林场、陕西宁陕县宁 西林业局、甘肃小陇山林业实验局东岔林场等单位 在采样工作中给予的帮助, 感谢山西大学张峰教 授、西北大学岳明教授、西北农林大学张文辉教授、
陕西中医药大学张明英老师在野外采样过程中给 予的协调和支持，感谢中国科学院武汉植物园左娟 研究员帮助修改英文摘要, 感谢中国科学院武汉植 物园江明喜研究员对本研究的支持。

\section{参考文献}

Bedi S, Mehta S, Sharma S, Vashist KK (2009) Nitrogen nutrition and efficiency of seed reserve mobilization during germination in winter maize cv. Buland. Journal of New Seeds, 10, 57-61.

Bu HY, Chen XL, Xu XL, Liu K, Jia P, Du GZ (2007) Seed mass and germination in an alpine meadow on the eastern Tsinghai-Tibet Plateau. Plant Ecology, 191, 127-149.

Bu HY, Du GZ, Chen XL, Xu XL, Liu K, Wen SJ (2008) Community-wide germination strategies in an alpine meadow on the eastern Qinghai-Tibet Plateau: Phylogenetic and life-history correlates. Plant Ecology, 195, 87-98.

Caliskan S, Makineci E (2020) Carbon and nitrogen of seed and some germination parameters at different test temperatures in Anatolian black pine populations. Journal of Sustainable Forestry, 39, 23-34.

Chen XL, Wang F, Ding QD (2017) Effect of temperature and hormone of different provenance to Cercidiphyllum japonicum Sieb. et Zucc. seed germination. Journal of Sichuan Forestry Science and Technology, 38(6), 34-39. (in Chinese with English abstract) [陈学龙, 王飞, 丁全定 (2017) 温 度和激素对不同种源连香树种子发芽的影响. 四川林业 科技, 38(6), 34-39.]

Cochrane A, Yates CJ, Hoyle GL, Nicotra AB (2015) Will among-population variation in seed traits improve the chance of species persistence under climate change? Global Ecology and Biogeography, 24, 12-24.

Dang HS, Zhang YJ, Jiang MX, Zhang QF (2010) Growth performance and range shift of the subalpine fir (Abies fargesii) in the Qinling Mountains, China. International Journal of Sustainable Development and World Ecology, 17, 162-171.

De Frenne P, Kolb A, Graae BJ, Decocq G, Baltora S, Schrijver AD, Brunet J, Chabrerie O, Cousina SAO, Dhondt R, Diekmann M, Gruwez R, Heinken T, Hermy M, Liira J, Saguez R, Shevtsova A, Baskin CC, Verheyen K (2011) A latitudinal gradient in seed nutrients of the forest herb Anemone nemorosa. Plant Biology, 13, 493-501.

Diao SF, Shao WH, Jiang JM, Dong RX, Sun HG (2014) Phenotypic diversity in natural populations of Sapindus mukorossi based on fruit and seed traits. Acta Ecologica Sinica, 34, 1451-1460. (in Chinese with English abstract) [ᄀ松锋, 邵文豪, 姜景民, 董汝湘, 孙洪刚 (2014) 基于 种实性状的无患子天然群体表型多样性研究. 生态学报, 34, 1451-1460.]

Donohue K (2002) Germination timing influences natural 
selection on life-history characters in Arabidopsis thaliana. Ecology, 83, 1006-1016.

Evans JR (1989) Photosynthesis and nitrogen relationships in leaves of $\mathrm{C}_{3}$ plants. Oecologia, 78, 9-19.

Fait A, Angelovici R, Less H, Ohad I, Urbanczyk-Wochniak E, Fernie AR, Galili G (2006) Arabidopsis seed development and germination is associated with temporally distinct metabolic switches. Plant Physiology, 142, 839-854.

Feng CY (2012) Study on seed germination characteristic of Cercidiphyllum japonicum Sicb. et Zucc. Hubei Forestry Science and Technology, (1), 9-12. (in Chinese with English abstract) [冯朝元 (2012) 珍稀树种连香树种子发 芽特性的研究. 湖北林业科技, (1), 9-12.]

Fraaije RGA, ter Braak CJF, Verduyn B, Breeman, LBS, Verhoeven JTA, Soons MB (2015) Early plant recruitment stages set the template for the development of vegetation patterns along a hydrological gradient. Functional Ecology, 29, 971-980.

Groom PK, Lamont BB (2010) Phosphorus accumulation in Proteaceae seeds: A synthesis. Plant and Soil, 334, 61-72.

Gu YJ, Luo JX, Wu YW, Cao XJ (2009) Phenotypic diversity in natural populations of Picea balfouriana in Sichuan, China. Chinese Journal of Plant Ecology, 33, 291-301. (in Chinese with English abstract) [辜云杰, 罗建勋, 吴远伟, 曹小军 (2009) 川西云杉天然种群表型多样性. 植物生 态学报, 33, 291-301.]

Guo H, Mazer SJ, Du GZ (2010) Geographic variation in seed mass within and among nine species of Pedicularis (Orobanchaceae): Effects of elevation, plant size and seed number per fruit. Journal of Ecology, 98, 1232-1242.

Han A, Kim H, Jung JB, Park PS (2018) Seed germination and initial seedling survival of the subalpine tree species, Picea jezoensis on different forest floor substrates under elevated temperature. Forest Ecology and Management, 429, 579-588.

He D, Wei XZ, Li LF, Jiang MX, Yu J, Yang JY (2009) Population structure and dynamics of Cercidiphyllum japonicum in riparian zones of the Shennongjia Mountains region, Central China. Chinese Journal of Plant Ecology, 33, 469-481. (in Chinese with English abstract) [何东, 魏新增, 李连发, 江明喜, 喻杰, 杨敬元 (2009) 神农架山地河岸 带连香树的种群结构与动态. 植物生态学报, 33, 469-481.]

He QH, Yang SZ, Li YG, Shen X, Liu XH (2018) Phenotypic variations in seed and fruit traits of Liquidambar formosana populations. Chinese Journal of Plant Ecology, 42, 752-763. (in Chinese with English abstract) [何庆海, 杨少宗, 李因 刚, 沈金金, 柳新红 (2018) 枫香树种群种子与果实表型性 状变异分析. 植物生态学报, 42, 752-763.]

He YM, Li QF, He X, Fan RY, Duan RH, Liu Y (2018) Effects of environmental factors on seed germination and seedling establishment of Caryopteris mongolica. Acta Ecologica Sinica, 38, 4724-4732. (in Chinese with English abstract)
[贺一鸣, 李青丰, 贺晓, 樊如月, 段茹晖, 刘洋 (2018) 环境因子对蒙古获种子萌发及幼苗建成的影响. 生态学 报, 38, 4724-4732.]

Hooper ER, Legendre P, Condit R (2005) Barriers to forest regeneration of deforested and abandoned land in Panama. Journal of Applied Ecology, 42, 1165-1174.

Huang ZY, Liu SS, Bradford KJ, Huxman TE, Venable DL (2016) The contribution of germination functional traits to population dynamics of a desert plant community. Ecology, 97, 250-261.

Isagi $\mathrm{Y}$, Kudo M, Osumi K, Sato $\mathrm{T}$, Sakio H (2005) Polymorphic microsatellite DNA markers for a relictual angiosperm Cercidiphyllum japonicum Sieb. et Zucc. and their utility for Cercidiphyllum magnificum. Molecular Ecology Notes, 5, 596-598.

Jiang C, Wang F, Yu XY, Mu XM, Yang WM, Liu SJ (2013) Spatial and temporal variation of surface water vapor over northern and southern regions of Qinling Mountains. Acta Ecologica Sinica, 33, 3805-3815. (in Chinese with English abstract) [蒋冲, 王飞, 喻小勇, 穆兴民, 杨旺明, 刘思洁 (2013) 秦岭南北近地面水汽时空变化特征. 生态学报, 33, 3805-3815.]

Kubo M, Sakio H, Shimano K, Ohno K (2004) Factors influencing seedling emergence and survival in CercidiphyIlum japonicum. Folia Geobotanica, 39, 225-234.

Lai JS, Li QM, Xie ZQ (2003) Seed germinating characteristics of the endangered plant Abies chensiensis. Acta Phytoecologica Sinica, 27, 661-666. (in Chinese with English abstract) [赖江山, 李庆梅, 谢宗强 (2003) 濒危 植物秦岭冷杉种子萌发特性的研究. 植物生态学报, 27 , 661-666.]

Li N, Bai B, Lu CH (2011) Recruitment limitation of plant population: From seed production to sapling establishment. Acta Ecologica Sinica, 31, 6624-6632. (in Chinese with English abstract) [李宁, 白冰, 鲁长虎 (2011) 植物种群 更新限制一从种子生产到幼树建成. 生态学报, 31, 6624-6632.]

Li WL, Zhang XP, Hao CY, Zhang H (2008) Characteristics of seed germination of the rare plant Cercidiphyllum japonicum. Acta Ecologica Sinica, 28, 5445-5453. (in Chinese with English abstract) [李文良, 张小平, 郝朝运, 张慧 (2008) 珍稀植物连香树 (Cercidiphyllum japonicum) 的种 子萌发特性. 生态学报, 28, 5445-5453.]

Li X, Yin X, Yang SH, Yang YQ, Qian M, Zhou YL, Zhang C, Du Y, Yang YP (2015) Variations in seed characteristics among and within Stipa purpurea populations on the Qinghai-Tibet Plateau. Botany, 93, 651-662.

Li YG, Liu XH, Ma JW, Shi CG, Zhu GQ (2014) Phenotypic variations in populations of Phoebe chekiangensis. Chinese Journal of Plant Ecology, 38, 1315-1324. (in Chinese with English abstract) [李因刚, 柳新红, 马俊伟, 石从广, 朱光 权 (2014) 浙江楠种群表型变异. 植物生态学报, 38, 1315-1324.] 
Liu HL, Zhang YK, Zhang DY, Yin LK, Zhang YM (2012) Variation in fruit and seed traits and seed germination among different populations of Eremosparton songoricum. Chinese Journal of Plant Ecology, 36, 802-811. (in Chinese with English abstract) [刘会良, 张永宽, 张道远, 尹林克, 张元明 (2012) 不同居群准噶尔无叶豆果实和种子特性 及种子萌发差异. 植物生态学报, 36, 802-811.]

Liu ZL, Yu MK, Ma Y, Tang LZ, Fang SZ (2011) A trend surface analysis of geographic variation in the traits of seeds and seedlings from different Quercus acutissima provenances. Acta Ecologica Sinica, 31, 6796-6804. (in Chinese with English abstract) [刘志龙, 虞木奎, 马跃, 唐罗忠, 方升佐 (2011) 不同种源麻栎种子和苗木性状地理变异趋势面分 析. 生态学报, 31, 6796-6804.]

Ma YL, Zhang JH, Li XR, Zhang SY, Lan HY (2016) Effects of environmental stress on seed germination and seedling growth of Salsola ferganica (Chenopodiaceae). Acta Ecologica Sinica, 36, 456-463.

Mao JF, Li Y, Liu YJ, Liu H, Wang XR (2007) Cone and seed characteristic of Pinus densata and their adaptive fitness implications. Journal of Plant Ecology (Chinese Version), 31, 291-299. (in Chinese with English abstract) [毛建丰, 李悦, 刘玉军, 刘影, 王晓茹 (2007) 高山松种实性状与 生殖适应性. 植物生态学报, 31, 291-299.]

Masaki T, Osumi K, Takahashi K, Hoshizaki K, Matsune K, Suzuki W (2007) Effects of microenvironmental heterogeneity on the seed-to-seedling process and tree coexistence in a riparian forest. Ecological Research, 22, 724-734.

Moles AT, Warton DI, Stevens RD, Westoby M (2007) Does a latitudinal gradient in seedling survival favour larger seeds in the tropics? Ecology Letters, 7, 911-914.

Murray BR, Brown AHD, Dickman CR, Crowther MS (2004) Geographical gradients in seed mass in relation to climate. Journal of Biogeography, 31, 379-388.

Rosbakh S, Poschlod P (2015) Initial temperature of seed germination as related to species occurrence along a temperature gradient. Functional Ecology, 29, 5-14.

Sakio H, Kubo M, Shimano K, Ohno K (2002) Coexistence of three canopy tree species in a riparian forest in the Chichibu Mountains, central Japan. Folia Geobotanica, 37, 45-61.

Shaban M (2013) Study on some aspects of seed viability and vigor. International Journal of Advanced Biological and Biomedical Research, 1, 1692-1697.

She CQ, Yang WX, Fang SZ, Shang XL (2009) Phenotypic diversity of natural Cyclocarya paliurus populations seed traits. Chinese Journal of Applied Ecology, 20, 2351-2356. (in Chinese with English abstract) [余诚棋, 杨万霞, 方升 佐, 尚旭岗 (2009) 青钱柳天然群体种子性状表型多样 性. 应用生态学报, 20, 2351-2356.]

Shen ZH, Jin YX, Zhao ZE, Wu JQ, Huang HD (2000) The structure and dynamics of the rare plant communities in subtropical mountain of China. Acta Ecologica Sinica, 20, 800-807. (in Chinese with English abstract) [沈泽吴, 金义
兴, 赵子恩, 吴金清, 黄汉东 (2000) 亚热带山地森林珍 稀植物群落的结构与动态. 生态学报, 20, 800-807.]

Soriano D, Orozco-Segovia A, Márquez-Guzmán J, Kitajima K, Buen AG, Huante P (2011) Seed reserve composition in 19 tree species of a tropical deciduous forest in Mexico and its relationship to seed germination and seedling growth. Annals of Botany, 107, 939-951.

Sudrajat DJ (2016) Genetic variation of fruit, seed, and seedling characteristics among 11 populations of white jabon in Indonesia. Forest Science and Technology, 12, 9-15.

Susko DJ, Lovett-Doust L (2000) Patterns of seed mass variation and their effects on seedling traits in Alliaria petiolata (Brassicaceae). American Journal of Botany, 87, 56-66.

Tian DS (2018) Effects of the supply levels and ratios of nitrogen and phosphorus on seed traits of Chenopodium glaucum. Chinese Journal of Plant Ecology, 42, 963-970. (in Chinese with English abstract) [田大栓 (2018) 氮磷供 应量及比例对灰绿藜种子性状的影响. 植物生态学报, 42, 963-970.]

Villellas J, García MB (2013) The role of the tolerance-fecundity trade-off in maintaining intraspecific seed trait variation in a widespread dimorphic herb. Plant Biology, 15, 899-909.

Wang BF, Zhang JB, Jiang ZP, Yang XH, Zhao YM (2008) Genetic variation of seed traits and its reproductive capacity of Haloxylon ammodendron. Journal of Arid Land Resources and Environment, 22, 167-173. (in Chinese with English abstract) [王葆芳, 张景波, 江泽平, 杨晓晖, 赵英 铭 (2008) 梭梭种子性状和繁殖力的遗传变异与评价. 干旱区资源与环境, 22, 167-173.]

Wang CH, Li JQ, Chen FQ, Yang Y (2011) Factors affecting seedling regeneration of Liquidambar formosana in the $L$. formosana forests in hilly regions of Southeast Hubei, China. Chinese Journal of Plant Ecology, 35, 187-194. (in Chinese with English abstract) [王传华, 李俊清, 陈芳清, 杨荣 (2011) 鄂东南低丘地区枫香林下枫香幼苗更新限 制因子. 植物生态学报, 35, 187-194.]

Wang J, Zhang XP, Li WL, Wang L, Wu JX, Chen YK (2010) Genetic diversity and genetic variation of populations endangered tree Cercidiphyllum japonicum. Bulletin of Botanical Research, 30, 208-214. (in Chinese with English abstract) [王静, 张小平, 李文良, 王否, 吴建勋, 陈一锟 (2010) 濒危植物连香树居群的遗传多样性和遗传分化研 究. 植物研究, 30, 208-214.]

Wang YL, Li Y (2008) Study on phenotypic diversity of cone and seed in natural populations of Picea crassifolia in Qilian Mountain, China. Journal of Plant Ecology (Chinese Version), 32, 355-362. (in Chinese with English abstract) [王娅丽, 李毅 (2008) 祁连山青海云杉天然群体的种实 性状表型多样性. 植物生态学报, 32, 355-362.]

Wei XZ, Wu H, Meng HJ, Pang CM, Jiang MX (2015) 
Regeneration dynamics of Euptelea pleiospermum along latitudinal and altitudinal gradients: Trade-offs between seedling and sprout. Forest Ecology and Management, 353, 232-239.

Wu H, Meng HJ, Wang ST, Wei XZ, Jiang MX (2018) Geographic patterns and environmental drivers of seed traits of a relict tree species. Forest Ecology and Management, 422, 59-68.

Wu ZY (1980) Vegetation in China. Science Press, Beijing. (in Chinese) [吴征镒 (1980) 中国植被. 科学出版社, 北京.]

Xiong D, Chen FJ, Liang HW, Wang YB, Yang TZ (2007) Study on seed germination of the rare endangered plant Cercidiphyllum japonicum. Journal of Fujian Forestry Science and Technology, 34(1), 36-39. (in Chinese with English abstract) [熊丹, 陈发菊, 梁宏伟, 王玉兵, 杨天忠 (2007) 珍稀濒危植物连香树种子萌发的研究. 福建林业 科技, 34(1), 36-39.]

Yang RH, Sun BS, Liu SY (2012) Resource distribution and endangered mechanism of genus Cercidiphyllum in Qinling region. Journal of Northeast Forestry University, 40(6), 19-22. (in Chinese with English abstract) [杨荣慧, 孙宝胜, 刘守阳 (2012) 秦岭地区连香树分布现状与濒危机理. 东北林业大学学报, 40(6), 19-22.]

Yang ZL, Yang X, Tan ZF, Gan GB, Shu X, Yu HH, Liu RN (2009) Variation of seed characters of Magnolia officinalis from different provenances and families. Journal of Central South University of Forestry and Technology, 29(5), 49-55. (in Chinese with English abstract) [杨志玲, 杨旭, 谭梓峰, 甘光标, 舒香, 于华会, 刘若楠 (2009) 厚朴不同种源及
家系种子性状的变异. 中南林业科技大学学报, 29(5), 49-55.]

Yuan LJ, Fang XM, Cui B, Cheng XM, Li HY, Ye YZ (2007) Study on pollination biology of endangered plant Cercidiphyllum japonicum. Journal of Henan Agricultural University, 41, 647-650, 654. (in Chinese with English abstract) [袁丽洁, 方向民, 崔波, 程喜梅, 李红运, 叶永 忠 (2007) 濒危植物连香树的传粉生物学研究. 河南农 业大学学报, 41, 647-650, 654.]

Zang RG (1999) Gap Dynamics and Forest Biodiversity. China Forestry Publishing House, Beijing. (in Chinese) [㶓润国 (1999) 林隙动态与森林生物多样性. 中国林业出版社, 北京.]

Zhang BP (2019) Ten major scientific issues concerning the study of China's north-south transitional zone. Progress in Geography, 38, 305-311. (in Chinese with English abstract) [张百平 (2019) 中国南北过渡带研究的十大科学问题. 地理科学进展, 38, 305-311.]

Zhu JJ, Kang HZ, Xu ML (2007) Natural regeneration barriers of Pinus sylvestris var. mongolica plantations in southern Keerqin sandy land, China. Acta Ecologica Sinica, 27, 4086-4095. (in Chinese with English abstract) [朱教君, 康 宏樟, 许美玲 (2007) 科尔沁沙地南缘樟子松 (Pinus sylvestris var. mongolica)人工林天然更新障碍. 生态学报, 27, 4086-4095.]

(责任编委: 王志恒 责任编辑: 黄祥忠)

\section{附录 Supplementary Material}

附录1 中国分布区北缘连香树研究样点的月均温

Appendix 1 Mean monthly temperature of study sites for the northern marginal Cercidiphyllum japonicum populations in China http://www.biodiversity-science.net/fileup/PDF/2020095-1.pdf 
李晶, 周天阳, 鲁雪丽, 李新涛, 孙斌, 孟红杰 (2020) 珍稀植物连香树在其中国分布区北缘的种子性状及幼苗更新限制. 生物多样性, 28, 1161-1173. http://www.biodiversityscience.net/CN/10.17520/biods.2020095

附录1 中国分布区北缘连香树研究样点的月均温

Appendix 1 Mean monthly temperature of study sites for the northern marginal Cercidiphyllum japonicum populations in China

\begin{tabular}{|c|c|c|c|c|c|}
\hline & 天水 Tianshui & 宁陕 Ningshan & 奕川 Luanchuan & 沁水 Qinshui & 济源 Jiyuan \\
\hline 1 月平均温度 Mean monthly temperature in January $\left({ }^{\circ} \mathrm{C}\right)$ & -4 & -3 & -4 & -7 & -3 \\
\hline 2 月平均温度 Mean monthly temperature in February $\left({ }^{\circ} \mathrm{C}\right)$ & -1 & -2 & -2 & -4 & 0 \\
\hline 3 月平均温度 Mean monthly temperature in March $\left({ }^{\circ} \mathrm{C}\right)$ & 4 & 3 & 3 & 2 & 6 \\
\hline 4 月平均温度 Mean monthly temperature in April $\left({ }^{\circ} \mathrm{C}\right)$ & 10 & 9 & 9 & 8 & 13 \\
\hline 5 月平均温度 Mean monthly temperature in May $\left({ }^{\circ} \mathrm{C}\right)$ & 14 & 13 & 14 & 13 & 18 \\
\hline 6 月平均温度 Mean monthly temperature in June $\left({ }^{\circ} \mathrm{C}\right)$ & 18 & 17 & 18 & 18 & 23 \\
\hline 7 月平均温度 Mean monthly temperature in July $\left({ }^{\circ} \mathrm{C}\right)$ & 21 & 20 & 20 & 20 & 24 \\
\hline 8 月平均温度 Mean monthly temperature in August $\left({ }^{\circ} \mathrm{C}\right)$ & 19 & 19 & 19 & 18 & 23 \\
\hline 9 月平均温度 Mean monthly temperature in September $\left({ }^{\circ} \mathrm{C}\right)$ & 14 & 14 & 15 & 13 & 18 \\
\hline 10 月平均温度 Mean monthly temperature in October $\left({ }^{\circ} \mathrm{C}\right)$ & 9 & 9 & 9 & 8 & 13 \\
\hline 11 月平均温度 Mean monthly temperature in November $\left({ }^{\circ} \mathrm{C}\right)$ & 3.2 & 3 & 3.3 & 1.4 & 5.3 \\
\hline 12 月平均温度 Mean monthly temperature in December $\left({ }^{\circ} \mathrm{C}\right)$ & -1.9 & -1.7 & -2.2 & -5 & -0.9 \\
\hline
\end{tabular}

